\title{
Development and validation of an experimental life support system for assessing the effects of global climate change and environmental contamination on estuarine and coastal marine benthic communities
}

FRANCISCOJ.R.C.COELHO*, RUIJ. M. ROCHA*, ANA C. C. PIRES*, BRUNOLADEIRO*, JOSÉ M. CASTANHEIRA†, RODRIGOCOSTA ANA ISABEL LILLEBØ*, RUI RIBEIRO, RUTH PEREIRA, , I, ISABEL LOPES*, CATARINA MARQUES*, MATILDE MOREIRA-SANTOS, RICARDO CALADO*, DANIEL F. R. CLEARY* and NEWTON C. M. GOMES*

*Department of Biology \& CESAM, University of Aveiro, Campus de Santiago, Aveiro 3810-193, Portugal, †Department of Physics \& CESAM, University of Aveiro, Campus de Santiago, Aveiro 3810-193, Portugal, \$Centre of Marine Sciences, Algarve University, Gambelas Campus, Faro 8005-139, Portugal, §Instituto do Mar (IMAR-CMA), Department of Life Sciences, University of Coimbra, Coimbra 3004-517, Portugal, - Departament of Biology, Faculty of Sciences of the University of Porto, Rua do Campo Alegre s/n, 4169-007 Porto, Portugal, ||CESAM, University of Aveiro, Campus de Santiago, Aveiro 3810-193, Portugal

\begin{abstract}
An experimental life support system (ELSS) was constructed to study the interactive effects of multiple stressors on coastal and estuarine benthic communities, specifically perturbations driven by global climate change and anthropogenic environmental contamination. The ELSS allows researchers to control salinity, pH, temperature, ultraviolet radiation (UVR), tidal rhythms and exposure to selected contaminants. Unlike most microcosms previously described, our system enables true independent replication (including randomization). In addition to this, it can be assembled using commercially available materials and equipment, thereby facilitating the replication of identical experimental setups in different geographical locations. Here, we validate the reproducibility and environmental quality of the system by comparing chemical and biological parameters recorded in our ELSS with those prevalent in the natural environment. Water, sediment microbial community and ragworm (the polychaete Hediste diversicolor) samples were obtained from four microcosms after 57 days of operation. In general, average concentrations of dissolved inorganic nutrients $\left(\mathrm{NO}_{3}{ }^{-} ; \mathrm{NH}_{4}{ }^{+}\right.$and $\left.\mathrm{PO}_{4}{ }^{-3}\right)$ in the water column of the ELSS experimental control units were within the range of concentrations recorded in the natural environment. While some shifts in bacterial community composition were observed between in situ and ELSS sediment samples, the relative abundance of most metabolically active bacterial taxa appeared to be stable. In addition, ELSS operation did not significantly affect survival, oxidative stress and neurological biomarkers of the model organism Hediste diversicolor. The validation data indicate that this system can be used to assess independent or interactive effects of climate change and environmental contamination on benthic communities. Researchers will be able to simulate the effects of these stressors on processes driven by microbial communities, sediment and seawater chemistry and to evaluate potential consequences to sediment toxicity using model organisms such as Hediste diversicolor.
\end{abstract}

Keywords: benthic communities, climate change, marine sediments, microbial ecology, microcosm, pyrosequencing

Received 25 November 2012; revised version received 27 March 2013 and accepted 14 April 2013

\section{Introduction}

One of the greatest scientific challenges currently faced by researchers worldwide is to understand how human activities alter ecosystems and how ecosystems will respond to future perturbations. A key question is to

Correspondence: Newton C. Marcial Gomes, tel. +351234370990, fax +351234370309, e-mail: gomesncm@ua.pt what extent changes in ocean temperature, acidity and UV radiation will affect contaminant toxicity and what impact this will have on the marine biota (Doney, 2010; Hader et al., 2011). Although there is increased awareness of the potential for interactions between climate change and chemical contaminants, we only have a rudimentary understanding of how multiple stressors interact to affect (communities of) organisms (Schiedek et al., 2007; Gao et al., 2012; Passow \& Carlson, 2012). 
Thus, it is important that we gain a mechanistic understanding of how anthropogenic stressors affect coastal and estuarine marine ecosystems. These biomes provide valuable ecosystem services such as fisheries, filtering, detoxification and carbon sequestration. However, they are among the most impacted of global ecosystems (Barbier et al., 2010).

The processes involved in ecosystem response to perturbation often occur over a wide range of temporal and spatial scales with unknown interactions, making it difficult to establish cause-effect relationships in natural systems (Benton et al., 2007). In particular, there is no standardized approach for the evaluation of global change effects on different marine ecosystems.

Small scale models, for example, microcosms, can be a useful tool to assess such complex global problems (Benton et al., 2007). Microcosms are simplified ecosystems, designed to simulate natural environments under controlled conditions (Roeselers et al., 2006). These model systems enable the testing of hypotheses and ecological theories on populations or communities with a high degree of experimental control and replication, which would be very difficult to achieve through field observation or in situ experimentation (Jessup et al., 2004; Benton et al., 2007). Moreover, microcosms allow researchers to perform experiments with potentially toxic contaminants, which would rarely (if ever) be carried out in the field.

In this study, we assess to what extent microcosm conditions affect sediment bacterial communities and the endobenthic species Hediste diversicolor (Müller, 1776, formerly known as Nereis diversicolor). Bacterial communities are fundamental players in every relevant geochemical cycle. However, despite the overwhelming importance of bacterial mediated processes, the potential impact of climate change on bacterial composition and activity is still poorly understood (Reid, 2011). Hediste diversicolor is a key species in shallow coastal systems: it is omnivorous, an active predator, and is highly prone to predation by waders, fish and crabs (Scaps, 2002). This species has been widely used as a model or sentinel organism in the assessment of sublethal contaminant impact in estuaries, both in the field and in laboratory microcosms (Moreira et al., 2006).

An important, but often overlooked, prerequisite when performing microcosm experiments is to determine whether the structural and functional properties of the source ecosystem are well represented in the microcosm, and the extent to which the experimental results are biased by the microcosm design and conditions (Leser, 1994). In this study, our main goals were to develop and evaluate an innovative experimental life support system (ELSS) designed to (i) study the interactive effects of multiple stressors on coastal and estuarine benthic communities, that is, environmental stressors resulting from climate change and contamination, and (ii) enable researchers to carry out complex but well-replicated experiments. We also aimed to develop a versatile system that could be assembled in different marine regions across the world using commercially available materials and equipment. The physical, chemical and biological parameters of marine environments can be highly variable at the regional scale. This variability determines, to a given extent, how intensively global climate change affects these environments. Therefore, it is important to develop tools to evaluate the applicability of current models in predicting changes in local ecosystem health and function.

\section{Materials and methods}

\section{ELSS basic architecture}

The basic concept of our ELSS was to provide a versatile framework for microcosm simulation of climate change scenarios in coastal and estuarine environments that could be easily replicated around the world. To achieve this goal, the system was developed using the following: (i) affordable materials and equipment, which are readily available in local or online stores (Table S1 for a list of the main material and equipment employed to assemble the ELSS, as well as their respective suppliers); and (ii) a modular construction system that will enable researchers to work over a wide range of configurations, thus allowing them to address specific research questions using statistically robust experimental designs.

The experimental life support system mimics fundamental aspects that condition biological activity in marine ecosystems, namely photoperiod, light intensity [including photosynthetically active radiation, (PAR)] and tidal cycles. In addition to this, researchers are also able to control temperature, ultraviolet radiation (UVR), salinity and $\mathrm{pH}$. Our ELSS is divided into two frames of 16 microcosms (32 in total) (glass tanks $25 \mathrm{~cm}$ high, $28 \mathrm{~cm}$ length and $12.4 \mathrm{~cm}$ width, each with a maximum functional water volume of approximately 31 ), which enable researchers to run up to eight treatments simultaneously, each one with a maximum of four independent replicates. All replicates can be arranged in a randomized split-plot design (Fig. 1 and Fig. S1).

Tidal cycle and water circulation control system. The ELSS is operated using synthetic saltwater, which is prepared by mixing freshwater, purified by a four stage reverse osmosis unit (Aqua-win RO-6080) with a commercially available salt mixture (Tropic Marin Pro Reef salt - Tropic Marine, Germany) (Fig. 1, B1 and B2). The water for tidal cycles is prepared $24 \mathrm{~h}$ before use, to allow salt and water to mix. No water recirculation is employed to avoid cross-contamination between experimental treatments and to avoid chemical artefacts that may be promoted by re-using the same water over time. Thus, this ELSS can be described as a flow-through 


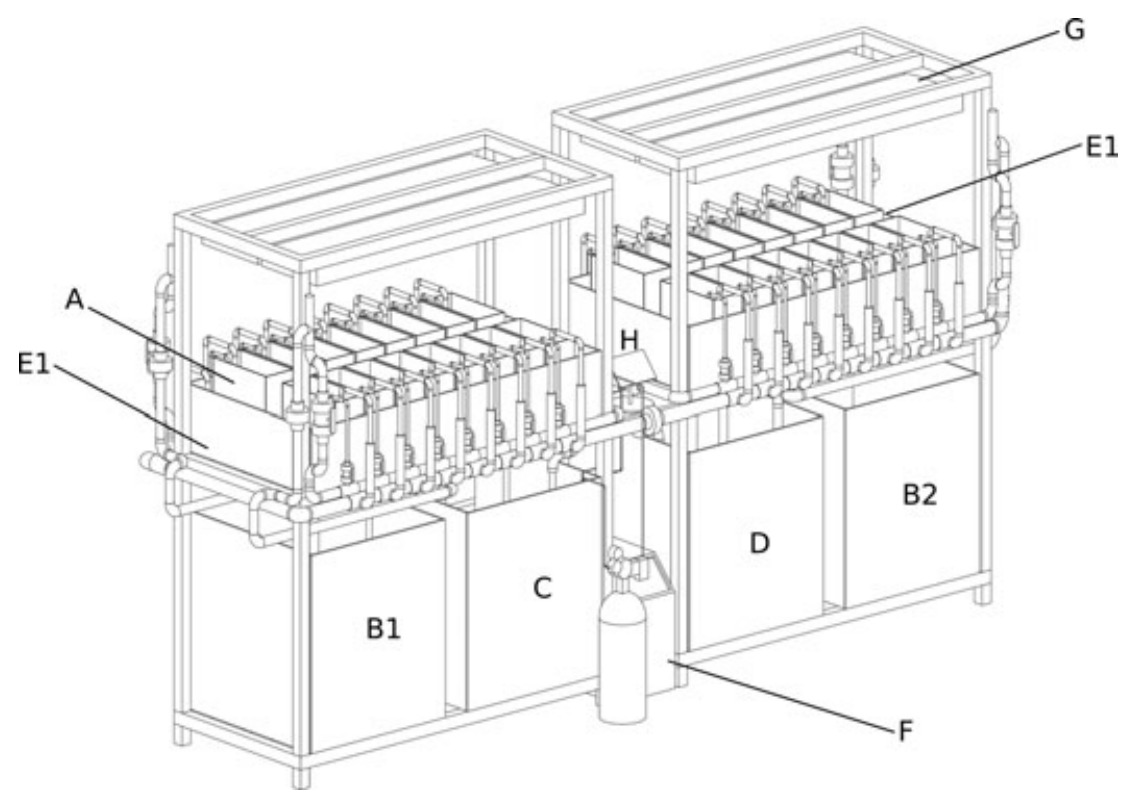

Fig. 1 Experimental life support system (ELSS) general scheme. A, independent microcosm; B, saltwater reservoir; C, acidified saltwater reservoir; $\mathrm{D}$, normal $\mathrm{pH}$ saltwater reservoir; $\mathrm{E}$, water bath; F, refrigerator; $\mathrm{G}$, lightning system (a vinyl frame can be included to isolate the light from the luminaires); $\mathrm{H}, \mathrm{pH}$ control system. More detailed schemes of the experimental life support system are given in the supporting information.

non-recirculated system operated with synthetic saltwater. Its hydraulic system enables microcosms to be operated under any desired tidal regime (e.g. diurnal, mixed, semi-diurnal). Each tidal regime is controlled as follows: newly prepared synthetic saltwater is pumped (Aquabee UP 3000) into the saltwater reservoirs (Fig. 1C and D) for $\mathrm{pH}$ adjustment (if necessary); the ELSS is equipped with four such reservoirs (each with an approximate volume of 230 l). For high tide events, saltwater is pumped using a submersible pump (Aquabee UP 3000) from reservoirs C and D (Fig. 1) through an independent pipe system of polyvinyl chloride (PVC) tubes into each microcosm. The saltwater flow rate is manually controlled by a PVC valve located above each microcosm (Fig. S1, S2 and S3). Low tide events are simulated using outflow submersible pumps (Rena flow $400{ }^{\circ} \mathrm{C}$ ), operated with digital timers; each glass tank (the microcosm) is equipped with a single pump positioned inside a PVC cylinder and protected with a mesh screen (to avoid clogging) (Fig. S4). During low tide events, the water is discharged from the microcosms through an outflow pipe, and drained to a collector.

$p H$ control system. Water $\mathrm{pH}$ can be manipulated by acidifying the water stocked in the tide reservoirs by bubbling $\mathrm{CO}_{2}$ through a diffuser (Fig. S5) (Gattuso \& Lavigne, 2009). The diffuser operates with a water pump (Aquabee UP 3000) to maximize $\mathrm{CO}_{2}$ gas mixing in saltwater. $\mathrm{CO}_{2}$ addition is controlled with a feedback system that includes a combination of a $\mathrm{pH}$ electrode connected to a controller $\left(\mathrm{V}^{2}\right.$ control $\mathrm{pH}$ controller, Tropical Marine Centre, Bristol, UK) and a pressure regulator with an integrated solenoid valve ( $V^{2}$ pressure regulator pro, Tropical Marine Centre, UK). The digital display of the controller allows visualization of actual $\mathrm{pH}$ in the saltwater reser- voirs and $\mathrm{pH}$ monitoring with the $\mathrm{pH}$ electrode. The controller opens the solenoid valve whenever $\mathrm{pH}$ rises above the set value; $\mathrm{CO}_{2}$ is then injected until water $\mathrm{pH}$ returns to the pre-set value. We tested the $\mathrm{pH}$ system under the experimental validation parameters to simulate a $\mathrm{pH}$ reduction of 0.3 units. The average $\mathrm{pH}$ value measured during 1 week, every 2 days during each low tide (Fig. S10), was $7.67 \pm 0.07$ (NBS scale).

Temperature control system. To compensate for potential temperature fluctuations during experimental trials, namely those promoted by the illumination system implemented in our ELSS (see below), about two thirds of microcosm were submerged into water bath tanks (Fig. 1E1 and E2). These water bath tanks are drilled in the bottom and connected through a $40 \mathrm{~mm}$ PVC pipe with a valve. The connection of both water bath tanks ensures the same temperature in all microcosms. However, in experiments with different temperatures the connection valve between the water bath tanks can be closed, allowing the utilization of two distinct water temperature treatments. The water in water bath tanks is continuously pumped by a canister filter pump (SunSun HW-302) through a cooler equipped with a thermostat (Teco TR10) set to the desired temperature. The canister filter pump (composed by mechanical filtration sponges and activated carbon to remove any debris from the freshwater in the bath) operates with a flow rate of $1000 \mathrm{l} \mathrm{h}^{-1}$ (Fig. S6). Four submersible $200 \mathrm{~W}$ heaters equipped with thermostats (Rena Cal 200) are placed inside the water bath tanks to modify water temperature to previously set values. The simultaneous operation of the cooling and heating system minimizes water temperature fluctuations to $\pm 0.5^{\circ} \mathrm{C}$. 
Lighting control system. The ELSS is equipped with 4 Reef$\mathrm{SET}^{\circledR}$, (Rees, Germany) programmable luminaire systems for diurnal light cycle and controlled UV simulation. Each luminaire holds four UV fluorescent tubes (SolarRaptor, T5/54W, Rees, Germany) and four full spectra fluorescent tubes (AquaLight, T5/54W/10000K, Bramsche, Germany) disposed alternately under a reflector (Figs S7 and S8). The luminaire system incorporates a dimming ballast that allows researchers to adjust the light intensity by varying the voltage supply. ReefSET ${ }^{\circledR}$ proprietary software enables the simulation of a range of scenarios by varying the percentage of light intensity (please see http://www.reefset.com).

\section{Water chemistry analysis}

Water samples for dissolved inorganic nutrient (nitrate $\mathrm{NO}_{3}{ }^{-}$, ammonium $\mathrm{NH}_{4}{ }^{+}$and o-phosphate $\mathrm{PO}_{4}{ }^{3-}$ ) determination were collected from each microcosm at the beginning of the experiment, after 21 days and at the end of the experiment. Water aliquots' were immediately filtered (Whatman GF/C glass-fibre filter) and stored frozen at $-20{ }^{\circ} \mathrm{C}$ until analysis. $\mathrm{NO}_{3}{ }^{-}$determination followed the 8039 method described in the Hach Spectrophotometer (DR 2000) standard analytical procedures (Hach, USA, DR2000, 44863-00). The determination of $\mathrm{NH}_{4}{ }^{+}$and $\mathrm{PO}_{4}{ }^{3-}$ concentrations was carried out following standard spectrophotometric methods described elsewhere (Limnologisk Metodik, 1992). The analytical quality control was ensured by duplicate samples and by the analysis of blanks between samples.

Visual inspection of $\mathrm{NO}_{3}{ }^{-}, \mathrm{NH}_{4}{ }^{+}$and $\mathrm{PO}_{4}{ }^{3-}$ histograms revealed significant deviations from normality. The distributions remained significantly deviant after logarithmic and square-root transformation. We, therefore, tested for significant differences in dissolved inorganic nutrient concentration among sampling events using a repeated measures permutational analysis of variance with the adonis() function (Vegan package) in R (http://www.r-project.org/; Accessed 4 May 2012). The script used is provided in the supporting information.

\section{Biological validation}

Sediment sampling. Four sediment cores were collected at the east margin of Mira channel $\left(40^{\circ} 37^{\prime} \mathrm{N}, 8^{\circ} 44^{\prime} \mathrm{W}\right)$, one of the main channels of the Ria de Aveiro lagoon (Portugal) in May 2011. The Ria de Aveiro is a shallow mesotidal coastal lagoon connected with the Atlantic Ocean through a single inlet, and characterized by four main channels with several secondary narrow channels, inner basins and extensive intertidal areas (Dias et al., 2001). Studies have shown that the Ria de Aveiro has a moderate level of eutrophication and low overall human influence when compared to other estuarine systems (Ferreira et al., 2003; Lopes et al., 2007). Plexiglass cores of undisturbed sediment samples $(10 \mathrm{~cm}$ deep, $27 \mathrm{~cm}$ length and $10.6 \mathrm{~cm}$ width) were collected and each core transferred directly into individual microcosms (four in total) of the ELSS (Fig. 1A). Microcosms containing the sediment were taken back to the laboratory and connected to the
ELSS less than $2 \mathrm{~h}$ after sampling. The ELSS was operated continuously during 57 days.

Experimental validation parameters. The ELSS system was programmed to simulate the specific seasonal characteristics of the coastal lagoon system (Ria de Aveiro) at the sampling site where and when sediment cores were collected. Salinity was adjusted to simulate the conditions recorded at the sampling location and kept constant $(32.6 \pm 1.5)$ during the experiment, with synthetic saltwater being prepared as described above in the 'tidal cycle and water circulation control system' section. Prior to each high tide, water salinity was checked. All microcosms were exposed to a uniform semi-diurnal tidal regime, experiencing two high tides and two low tides daily. Each tidal cycle took approximately $1 \mathrm{~min}$. The duration of each tidal event minimizes $\mathrm{pH}$ and salinity fluctuations between the reservoirs and the microcosms. The minimum and maximum water levels above the sediment surface were approximately $5 \mathrm{~cm}$ (low tide) and $10 \mathrm{~cm}$ (high tide). During each tidal cycle about $50 \%$ of the water volume of each microcosm was exchanged $(\sim 1.51)$, thus simulating the water renewal percentage recorded for the central area of the estuarine system recreated in our ELSS (Ria de Aveiro) (Dias et al., 2001).

Water $\mathrm{pH}$ was adjusted to 8.0 and water temperature to $19^{\circ} \mathrm{C}$, and the average values were recorded at the sampling location. The average $\mathrm{pH}$ monitored in the system was $7.97 \pm 0.07$ (NBS scale). With the luminaires system set to its maximum power, the PAR value measured for the full spectrum fluorescent lamps was $260.50 \pm 56.30 \mu \mathrm{mol}$ photons $\mathrm{m}^{-2} \mathrm{~s}^{-1}$, and the UV-A $(320-400 \mathrm{~nm})$ irradiance emitted by the UV lamps was $2875.91 \pm 264.62 \mathrm{~mW} \mathrm{~m}^{-2}$ (Lamp spectrum - Fig. S9, and measurement details can be consulted in supporting information). To mimic summer photoperiod and light conditions at Portuguese latitudes during the time of sampling, a $14 \mathrm{~h}$ diurnal light cycle was simulated, with light intensity varying from 50 to $100 \%$ of the total fluorescent tube intensity (Table S2). Since UV-A radiation is practically unaffected by changes in ozone depletion and plays an important role in biological systems, including photo-repair mechanisms (Bargagli, 2005), a similar amount of UV-A integrated irradiance was maintained constant among microcosms. This was achieved by activating the UV lamps for four hours a day at maximum intensity and filtering the UV-B component with a glass panel in the luminaires.

\section{Active bacterial community profiling}

RNA extraction, denaturing gradient gel electrophoresis and pyrosequencing. Four composite samples each of four sediment cores (ca. $1 \mathrm{~cm}$ of top sediment with a $1 \mathrm{~cm}$ diameter) were taken in situ (ConBs), and from the microcosm after 21 days (ConIs) and 57 days (ConFs) of operation. Environmental samples were collected at the study site, separated at least $1 \mathrm{~m}$ from each other. Microcosm samples were obtained from four independent microcosms. Approximately, $1 \mathrm{~g}$ of the aerobic sediment layer was directly transferred into a $2.0-\mathrm{ml}$ screw cap tube containing Lysing Matrix E (FastRNA ${ }^{\circledR}$ Pro 
Soil-Direct Kit, Qbiogene Inc.,CA, USA) and immediately immersed in liquid nitrogen (Liu et al., 2011). Samples were kept at $-80{ }^{\circ} \mathrm{C}$ until RNA extraction.

Total RNA was isolated from sediment samples using the FastPrep ${ }^{\circledR}$ Instrument (Qbiogene, Inc, CA, USA), for $40 \mathrm{~s}$ at a speed setting of 6.0 according to the manufacturer's instructions. Residual DNA was removed using Turbo DNA-free kit (Applied Biosystems, Austin, TX, USA). Total RNA was then converted to single stranded cDNA using random hexamerprimed reverse transcription by applying SuperScript ${ }^{\circledR}$ III Reverse Transcriptase Kit (Invitrogen, Carlsbad, CA, USA). The complete removal of DNA was confirmed by PCR. Universal bacterial primers U27 and 1492R were used to amplify ca. $1450 \mathrm{bp}$ of the $16 \mathrm{~S}$ rRNA cDNA (Weisburg et al., 1991). Specific products were detected in cDNA samples after reverse transcription, but not in their corresponding source RNA samples (data not shown).

Denaturing gradient gel electrophoresis (DGGE) was used to monitor structural variation in bacterial communities in ConBs, ConIs and ConFs. Briefly, a nested PCR approach was used to amplify the 16S rRNA gene sequence from the samples. For the first PCR, the universal bacterial primers U27 and 1492R were used. For the second PCR, $1 \mu \mathrm{l}$ of the product of the first PCR was used as template with bacterial DGGE primers 968F-GC and 1401R (ca. 433 bp) (Nübel et al., 1996). The GC-clamped amplicons were applied to a double-gradient polyacrylamide gel containing 6-10\% acrylamide (Rotiphorese) with a gradient of $40-58 \%$ of denaturants. The run was performed in Tris-acetate-EDTA buffer $(0.5 \mathrm{M}$ Tris-Base, Sigma, $0.05 \mathrm{M}$ EDTA, Sigma; $0.1 \mathrm{M} \mathrm{CH}_{3} \mathrm{CO}_{2} \mathrm{Na}$, Sigma, pH 8.0) at $60^{\circ} \mathrm{C}$ at a constant voltage of $220 \mathrm{~V}$ for $16 \mathrm{~h}$ on a DCode vertical electrophoresis apparatus (universal mutation detection system; Bio-Rad). The DGGE gels were silver stained (Heuer et al., 2001). The processing of the DGGE gels was carried out using the Bionumerics software 6.6 (Applied Maths, Kortrijk, Belgium). A barcoded pyrosequencing approach was used for an in-depth microbial community analysis of ConBs and ConFs samples. Fragments of the 16S rRNA (cDNA) were sequenced for each sample with primers V3 Forward (5'-ACTCCTACGGGAGGCAG-3') and V4 Reverse (5'-TACNVRRGTHTCTAATYC-3') using the 454 Genome Sequencer FLX Titanium (Life Sciences Roche Diagnostics Ltd, West Sussex, UK). Sequences were analysed with the QIIME software package following published recommendations (Kuczynski et al., 2011). Details on sequence quality analysis and assignment can be found in supporting information. Sequences can be downloaded from the NCBI Short Read Archive (Study accession - SRP013200).

Two square square matrices (i) containing the abundance of all OTUs per sample generated with Qiime; and (ii) containing band intensity and position of the DGGE gel were imported into $\mathrm{R}$. Both were $\log _{10}(x+1)$ transformed and distance matrices constructed using the Bray-Curtis index with the vegdist() function in the vegan package in R (Oksanen et al., 2008). The Bray-Curtis index is one of the most frequently applied (dis) similarity indices used in ecology (Legendre \& Gallagher, 2001; Cleary, 2003; Cleary \& Genner, 2004a; Cleary et al., 2004b; de Voogd et al., 2009). Total rarefied OTU richness per sample was estimated with a self-written function (Gomes et al., 2010). Variation in OTU composition among treatments was tested for significance using the adonis() function. In the adonis() analysis, the Bray-Curtis distance matrix of OTU composition was the response variable with treatment as independent variable. The number of permutations was set at 999; all other arguments used the default values set in the function. Variation in the relative abundance of the most abundant higher taxa (three most abundant phyla; three most abundant classes and the six most abundant orders) was tested for significance with an analysis of deviance using the $\operatorname{glm}()$ function in R. Since the data were proportional, a glm with the family argument set as binomial was first applied. However, the ratio of residual deviance to residual $\mathrm{df}$ in the models exceeded 1 , so the family was set to 'quasibinomial'. In the quasibinomial family, the dispersion is not fixed at one so it can model overdispersion.

$H$. diversicolor stocking in microcosms. In addition to $H$. diversicolor, other marine invertebrates (the isopod Cyathura carinata, and the mudsnail Hydrobia ulvae) were introduced to the microcosms to ensure that all microcosms were colonized with meiofauna at minimal density levels. However, for the validation of the ELSS system, only data from $H$. diversicolor was used as this species has been widely used as a model or sentinel organism to assess contaminant impact in the field and laboratory (Moreira et al., 2006).

Invertebrate collection. Three invertebrate species were collected in June 2011 at two reference sites located in the Mondego $\left(40^{\circ} 08^{\prime} \mathrm{N}\right.$ and $8^{\circ} 50^{\prime} \mathrm{W}$; C. carinata) and Mira (H. diversicolor and $H$. ulvae; $37^{\circ} 40^{\prime} \mathrm{N}$ and $8^{\circ} 45^{\prime} \mathrm{W}$ ) estuaries. More details about the sampling location and procedures can be found in the supporting information. Hediste diversicolor $(7 /$ microcosms), C. carinata $(4 /$ microcosm) and H. ulvae (20/microcosm) were introduced after 21 days to the microcosms. These organisms were retrieved from the sediment at the end of the experiment, counted and immediately frozen in liquid nitrogen and stored at $-80{ }^{\circ} \mathrm{C}$ until further analysis. Pools of 2-3 ragworms from each microcosm were weighed (fresh weight) and homogenized in ice-cold phosphate buffer (50 mM, pH $=7.0$ with $0.1 \%$ Triton X-100) $\left(1: 5 \mathrm{~m} \mathrm{v}^{-1}\right)$. Homogenates were centrifuged at $10.000 \mathrm{~g}$ for $10 \mathrm{~min}$ at $4{ }^{\circ} \mathrm{C}$ and supernatants were divided in aliquots and stored at $-80{ }^{\circ} \mathrm{C}$.

Biochemical parameters. The total content in protein of each aliquot was determined spectrophotometrically according to Bradford (1976) using bovine $\gamma$-globulin as standard. Catalase (CAT) activity was measured spectrophotometrically at $240 \mathrm{~nm}$, following Aebi (1984). Superoxide dismutase (SOD) activity was assessed spectrophotometrically at $505 \mathrm{~nm}$, using the RANSOD (RANDOX ${ }^{\mathrm{TM}}$, London) SOD kit and following the procedure described in the manual provided by the supplier. Glutatione S-transferase (GST) activity was measured spectrophotometrically at $340 \mathrm{~nm}$ following Habig et al. (1974). Acetylcholinesterase (AChE) activity was measured spectrophotometrically at $414 \mathrm{~nm}$, following Ellman et al. 
(1961). Enzyme activities were measured in triplicate and expressed in nmol of hydrolysed substrate per minute per mg of protein, except for CAT and SOD, which were expressed in $\mu \mathrm{mol}$ of hydrolysed substrate per minute per $\mathrm{mg}$ of protein and SOD units per gram of protein.

Lipid peroxidation (LPO) was evaluated through the quantification of by-products of the peroxidation of membrane lipids, like malondialdeyde (MDA), after their reaction with 2-thiobarbituric acid (TBA), following Buege \& Aust (1978). The concentration of thiobarbituric acid reactive substances (TBARS: $\varepsilon=1.56 \times 10^{6} \mathrm{M}^{-1} \mathrm{~cm}^{-1}$ ) was measured spectrophotometrically at $535 \mathrm{~nm}$ and expressed in nmols of MDA equivalents per $\mathrm{mg}$ of protein).

The average values recorded for each parameter, in the organisms exposed in the microcosm control units, were compared with in situ and laboratory values reported in the literature for $H$. diversicolor, collected in the same estuary during the same period of the year (Moreira et al., 2006). AChE, CAT, GST, SOD and LPO activity deviated significantly from normality (Shapiro-Wilk normality test, $P=0.046, P<0.001$, $P=0.013, P=0.007$, and $P=0.015$ respectively). With the exception of GST after logarithmic transformation (ShapiroWilk normality test, $P=0.112$ ), the deviations remained significant after logarithmic and square-root transformation. GST exhibited homogenous variances between groups (Bartlett test, chi-squared $=1.31, \mathrm{df}=1, \mathrm{P}=0.251$ ). We therefore tested AChE, CAT, GST, SOD and LPO for significant differences between microcosm and reported values in literature using the adonis() function and tested GST using a Student's t-test. In the adonis() analysis, the Euclidean distance matrix of enzyme activity was the response variable with treatment as independent variable. The number of permutations was set at 999; all other arguments used the default values set in the function.

\section{Results and discussion}

\section{Water nutrient validation}

During the experimental period, the concentrations of $\mathrm{NO}_{3}{ }^{-}$did not change significantly (Repeated measures adonis, $\left.F_{2,9}=5.35, R^{2}=0.543, P=0.09\right)$. $\mathrm{NO}_{3}{ }^{-}$varied from $29.96 \pm 1.10 \mu \mathrm{mol} \mathrm{l}^{-1}$ at the beginning, to $42.86 \pm 10.1 \mu \mathrm{mol} \mathrm{l}^{-1}$ after 21 days and $32.38 \pm$ $1.31 \mu \mathrm{mol} l^{-1}$ at the end of the experiment. $\mathrm{NH}_{4}{ }^{+}$varied from $0.87 \pm 0.27 \mu \mathrm{mol} \mathrm{l}^{-1}$ at the beginning, $1.35 \pm$ $0.74 \mu \mathrm{mol} \mathrm{l}^{-1}$ after 21 days and $1.42 \pm 0.48 \mu \mathrm{mol} \mathrm{l}^{-1}$ at the end of the experiment. There was no significant difference in $\mathrm{NH}_{4}{ }^{+}$concentration between sampling events (Repeated measures adonis, $F_{2,9}=1.29, R^{2}=$ $0.223, \quad P=0.27) . \quad \mathrm{PO}_{4}^{-3}$ varied from $1.07 \pm 0.05$ $\mu \mathrm{mol} \mathrm{l}^{-1}$ at the beginning to $1.12 \pm 0.05 \mu \mathrm{mol} \mathrm{l^{-1 }}$ after 21 days and $1.07 \pm 0.05 \mu \mathrm{mol} \mathrm{l}^{-1}$ at the end of the experiment (Repeated measures adonis analysis: $\mathrm{F}_{2,9}=1.33, R^{2}=0.229, P=0.35$ ) (Fig. S11). In summary, the environmental range of water parameters (temperature, salinity and $\mathrm{pH}$ ) and dissolved inorganic nutrients
$\left(\mathrm{NO}_{3}{ }^{-}, \mathrm{NH}_{4}{ }^{+}\right.$and $\left.\mathrm{PO}_{4}{ }^{-3}\right)$ measured in our ELSS validation were comparable to those recorded in several Portuguese coastal systems (Table S3).

\section{Biological validation}

Sediment bacterial diversity. Denaturing gradient gel electrophoresis (DGGE) fingerprinting was used first as a proxy (Cleary et al., 2012) to assess the effect of the microcosm on bacterial community structure. Ordination analysis of band profiles revealed significant differences (Adonis, $F_{2,9}=1.58, R^{2}=0.260, P=0.007$ ) in composition among sampling events (Fig. S12). A $16 \mathrm{~S}$ RNA cDNA-based barcode pyrosequencing approach enabled deeper characterization of sediment bacterial communities from ConBs and ConFs. Barcode pyrosequencing has been successfully used for in-depth studies of microbial diversity in several ecosystems (Roesch et al., 2007; Keijser et al., 2008; Gomes et al., 2010; Pires et al., 2012). Most sequence-based studies use DNA libraries. However, DNA from dormant cells, 'dead' cells or extracellular DNA may bias the results (Urich et al., 2008; Gaidos et al., 2011). RNA cDNA libraries, in contrast, represent more recent activity and allow insight into compositional differences and in situ activity of microbial community members in a given setting (Urich et al., 2008). To examine changes in OTU richness promoted by our ELSS, rarefaction curves were generated (Fig. S13) for ConBs and ConFs. Controlling for sample size ( $n=1800$ sequences), OTU richness varied from $751.75 \pm 12.76$ in ConBs to $519.64 \pm 8.23$ in ConFs. Rarefied OTU richness was clearly lower at the end of the experiment. Shifts in bacterial community composition were assessed using $\mathrm{PCO}$ ordination of bacterial OTUs (97\%) (Figure S14). Composition differed significantly (Adonis analysis: $\mathrm{F}_{1,6}=3.89$, $R^{2}=0.039, P=0.025$ ) between sampling events. Most of the abundant OTUs (large grey circles; $\geq 50$ sequences) were shared between both treatments. However, certain dominant populations (OTUs) showed stronger associations to either ConBs or ConFs samples.

Microcosm manipulation affected bacterial composition by reducing the number of rare OTUs and increasing the abundance of particular OTUs. This probably occurred because the microcosm is a more stable and less heterogeneous environment. Reduced disturbance may have allowed competitively superior groups to out-compete and effectively eliminate other species. This phenomenon is in line with the intermediate disturbances hypothesis (IDH) (Connell, 1978). Such an effect can also occur within different habitats in natural marine environments, which are commonly subjected to several levels of heterogeneity and disturbance regimes (Gingold et al., 2010). For example, Laverock 
Proteobacteria

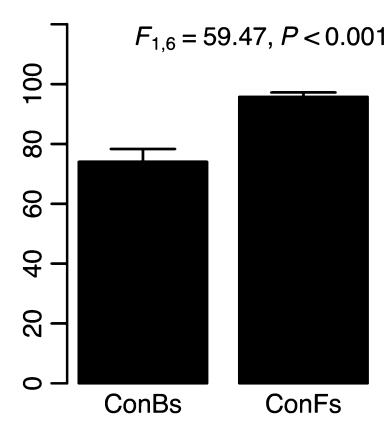

Deltaproteobacteria

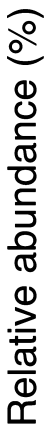

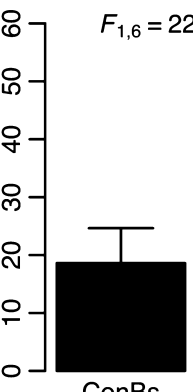

ConBs

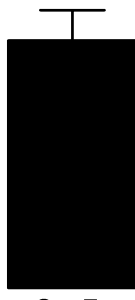

ConFs

Desulfobacterales

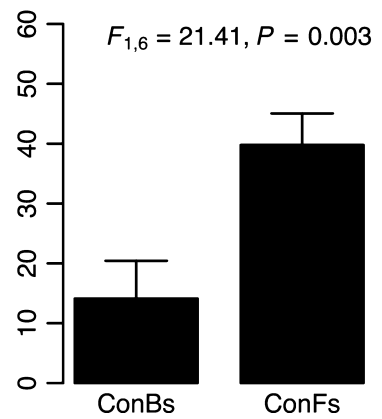

Actinobacteria

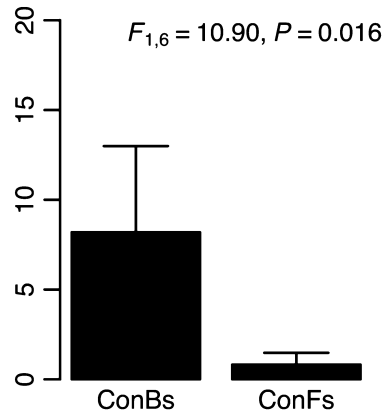

Gammaproteobacteria

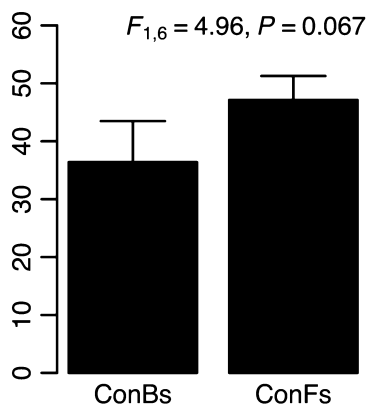

Chromatiales

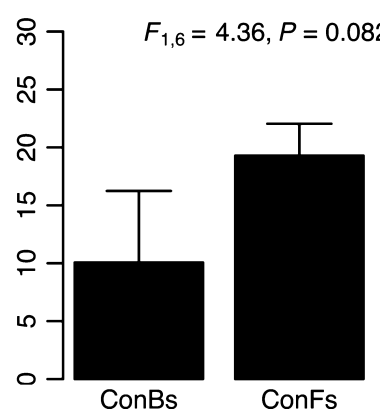

Cyanobacteria

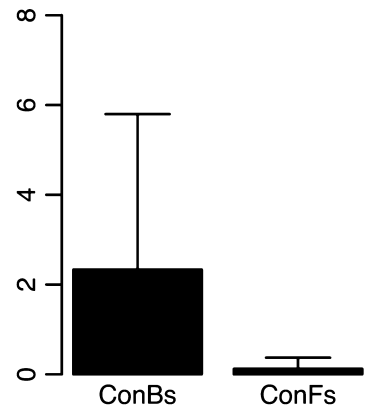

Methylococcales

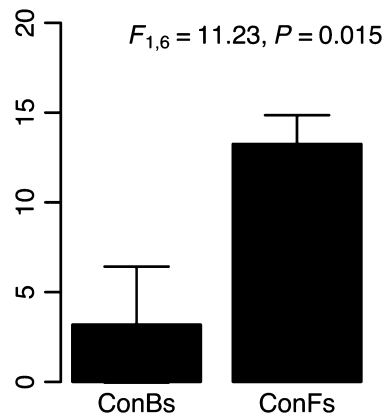

Acidimicrobiales

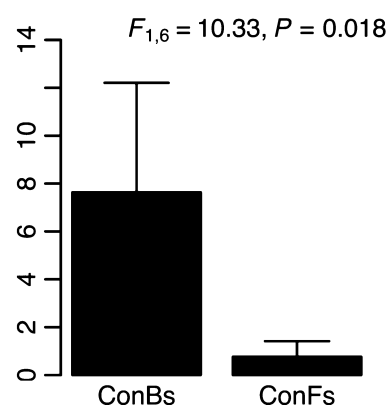

Alphaproteobacteria

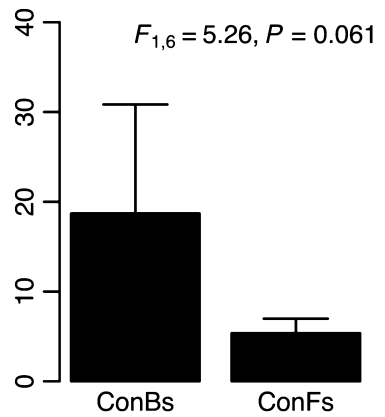

Rhodobacterales

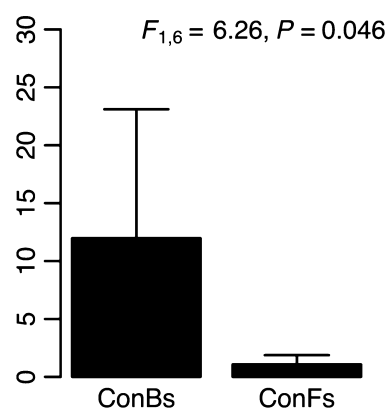

Fig. 2 Relative abundance of the most dominant bacterial taxa (three most abundant phyla; three most abundant classes and the six most abundant orders) in sediment collected in the environment (ConBs) and retrieved from the microcosm after 57 days of operation (ConFs). Summary of analysis of deviance (glm with'quasibinomial' family) is indicated above the bars. Note that the analysis of deviance was not performed on Cyanobacteria, since sequences affiliated with this group were not detected in all replicates in ConFs.

et al. (2010) showed that the presence of bioturbating shrimps in marine sediment habitats can induce changes in composition of sediment bacterial communities and increase bacterial diversity.

Bacterial composition analysis showed that $74.03 \pm$ $4.28 \%$ of all reads were assigned to the Proteobacteria at the beginning of the experiment. This rose to $95.74 \pm 1.47 \%$ at the end of the experiment. The different classes of this phylum are often abundant in marine sediment (Gomes et al., 2010; Jiang et al., 2009). Within the Proteobacteria, the Gammaproteobacteria was the most dominant class; their relative abundance ranged from $36.39 \pm 7.08 \%$, at the beginning of the experiment to $47.12 \pm 4.14 \%$ at the end. The Gammaproteobacteria is the largest Proteobacteria group in terms of diversity and includes a wide range of phenotypic and metabolic diversity with recognized importance (Kersters et al., 2006).

The relative abundance of the Deltaproteobacteria class increased significantly after microcosm manipulation from $18.60 \pm 6.04 \%$ at the beginning of the experiment to $42.70 \pm 5.25 \%$ at the end (Anova, $F_{1,6}, P=0.003$ ). Our results show that this trend was mainly related to an increase in the relative abundance of the Desulfobacterales order, which includes anaerobic sulphate reducing bacteria (SRB) (Fig. 2). SRB play an essential role in a variety of processes in anoxic marine sediment including organic matter turnover, pollutant detoxification and the carbon and sulphur cycles 
(Zhang et al., 2008). SRB use sulphate as an electron acceptor in the degradation of organic compounds resulting in the production of sulphide through the dissimilatory sulphate reduction pathway (Muyzer \& Stams, 2008). Our ELSS was programmed to simulate the central area of the Ria de Aveiro mesotidal system, where approximately $50 \%$ of the water volume is renewed between tides (Dias et al., 2001). However, the specific original sampling site is subject to higher water renewal percentages, leaving the sediment exposed to air during low tide. This implies that the microcosms simulated a more anoxic environment than the original sampling site, leading to an increased relative abundance of anaerobic Desulfobacterales. Introduction of the ragworm to the system might have also influenced bacterial community structure. Although bioturbation is generally associated with an increase in oxic zones in the sediment, infaunal activity can also augment anaerobic processes such as sulphate reduction (Bertics \& Ziebis, 2010). Nevertheless, the simulated conditions did not exclude important functional aerobic groups in sediment biogeochemical processes. The abundance of OTUs belonging to the Methylococcales order increased after microcosm manipulation from $3.19 \pm 3.23 \%$ at the beginning of the experiment to $13.26 \pm 1.60 \%$ at the end. This order includes several members that oxidize methane under aerobic or microaerobic conditions (Bowman, 2005).

In contrast to the Deltaproteobacteria, the abundance of Alphaproteobacteria declined from $18.70 \pm 12.14 \%$ at the beginning of the experiment to $5.36 \pm 1.60 \%$ at the end. This was mainly related to a reduction in the abundance of the Rhodobacterales order, which declined from $11.98 \pm 11.13 \%$ at the beginning of the experiment to $1.08 \pm 0.80 \%$ at the end. Within the Rhodobacterales, several OTUs belonging to the Rhodobacteraceae family were detected. Rhodobacteraceae includes the Roseobacter clade, one of the major marine groups; $20 \%$ of coastal and $15 \%$ of mixed-layer ocean bacterioplankton communities consist of members of this clade (Sørensen et al., 2005). Given that members of this group are likely present in water, their higher relative abundance in the sediment samples retrieved from the environment could be due to near-shore seawater infiltration, thus explaining their reduction following the microcosm experiment. In a previous study, Sørensen et al. (2005) found several phylotypes related to the Roseobacter clade in an endovaporitic microbial mat. The authors attributed this finding to seawater infiltration in the mat (Sørensen et al., 2005). Other less abundant phyla such as Cyanobacteria and Actinobacteria were also less abundant at the end of the experiment.

The distribution of dominant ( $\geq 50$ sequences) OTUs across all samples is visualized using a heatmap (Fig.
S15). Results from this analysis are in line with the pattern detected in the relative abundance analysis. Several abundant OTUs detected at the beginning of the experiment remained among the most dominant OTUs at the end of the experiment, including several known aerobic and anaerobic groups (e.g. Gammaproteobacteria - OTU 2987, OTU 2315, OTU 3254; Deltaproteobacteria - Desulfobacteraceae - OTU 3129; Methylococcales - 1648). As outlined above, several sulphate reducing bacterial OTUs increased their abundance in microcosm samples (e.g. Desulfobacteraceae OTUs - 1724; 1325), whereas members of the Rhodobacterales order declined in abundance at the end of the experiment (e.g. OTUs - 1569; 675).

Hediste diversicolor biochemical parameters. Hediste diversicolor has been indicated as an adequate sentinel species for transitional waters due to its wide distribution, sensitivity and its role in the functioning and structure of marine ecosystems (Scaps, 2002; Moreira et al., 2006; Bouraoui et al., 2009; Solé et al., 2009). Ragworms usually move actively around the sediment surface or within their burrow systems looking for food (Kristensen, 2001). Furthermore, they are both sediment eaters (Solé et al., 2009) and suspension feeders (Kristensen, 2001 and references cited), features that increase the chances of exposure to contaminants associated with different sediment components, overlying water and interstitial water.

At the end of the experiment, $96.40 \%$ of stocked $H$. diversicolor were recovered, indicating that the architecture and the conditions of the system did not compromise the survival of these organisms even during long-lasting exposure. Figure 3 shows boxplots for values recorded for each biochemical parameter monitored for $H$. diversicolor specimens stocked in the microcosms of our ELSS, as well as ranges of values available in the study of Moreira et al. (2006) for this species, collected in the same estuary and in the same period of the year. The comparability with organisms collected at the same period of the year is of particular importance as the influence of seasonal (e.g. water temperature) factors, physiological factors, sexual condition, gametogenesis period and behaviour in antioxidant enzyme levels is well known (Sun \& Zhou, 2008). Compared to the previous study of Moreira et al. (2006), no significant differences were observed in the activity of AChE (Adonis, $F_{1,7}=0.89, R^{2}=0.113, P=0.380 ; F_{1,17}=1.75$, $R^{2}=0.094, P=0.174$, comparing with in situ and laboratory data from Moreira et al., 2006 respectively), thus, denoting no neurological adverse effects of microcosm exposure in the polychaete. CAT and GST activities were significantly higher in this study in comparison to results obtained by Moreira et al. (2006) (Adonis for 
AChE

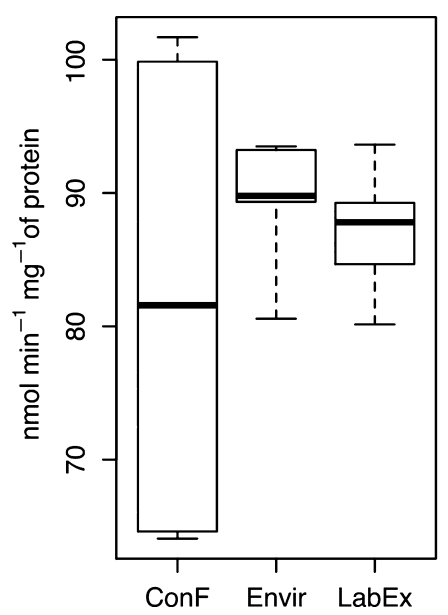

CAT

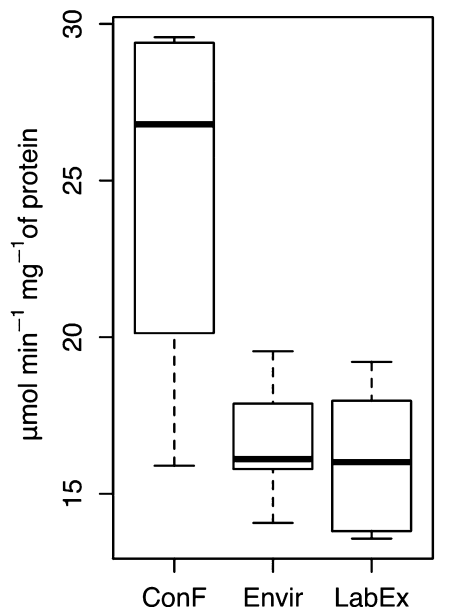

GST

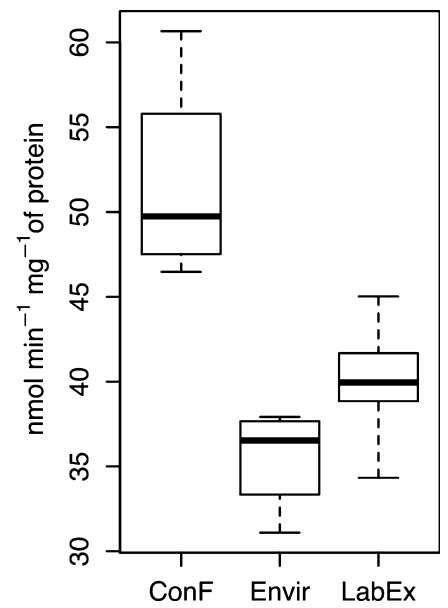

SOD
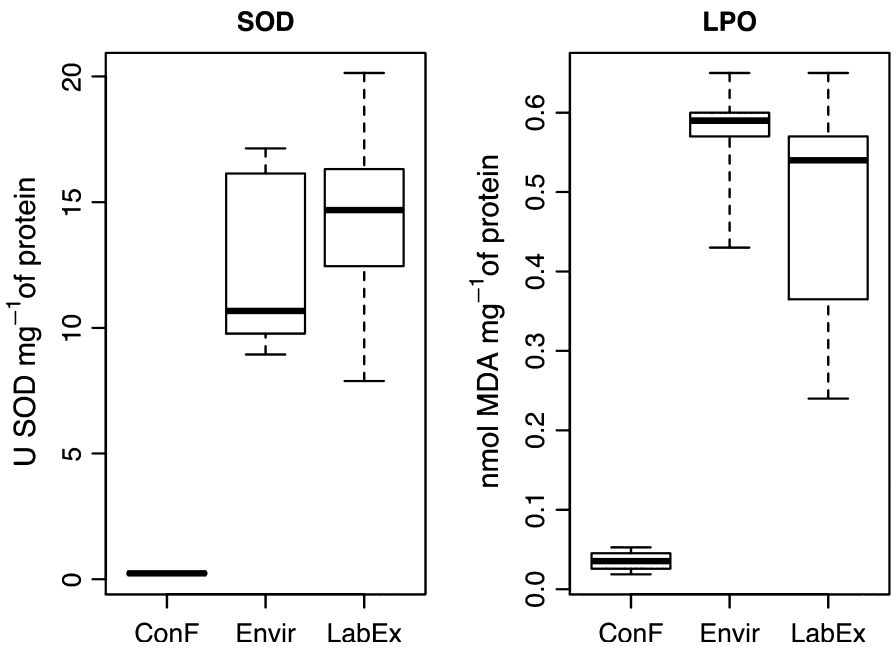

Fig. 3 Boxplot of the values recorded for each biochemical parameter measured in Hediste diversicolor after 36 days in the microcosms (ConF) and reported in the literature for in situ (Envir) and laboratory values (LabEx) of the same species collected at the same site and season (Moreira et al., 2006). The boxed area represents the mean \pm quartile and the whiskers extend to the minimum and maximum values.

CAT: $F_{1,7}=6.66, R^{2}=0.487, P=0.061 ; F_{1,17}=16.67$, $R^{2}=0.495, P=0.002$ and Student's t-test for GST: $t_{4,5}=5.6, P<0.001$ and $t_{4,15}=5.6, P<0.001$ respectively, when compared with laboratory and in situ data for each enzyme). However, the differences registered in GST activity between the present work and the results obtained by Moreira et al. (2006) with organisms exposed, under controlled conditions, in the laboratory was $22 \%$, which is close to the $20 \%$ threshold commonly considered within the normal range of activity of the enzyme and to have no biological significance (Olsen et al., 2001). The activity measured for SOD and LPO in $H$. diversicolor exposed in the ELSS was significantly lower than that reported by the latter authors (Adonis for SOD: $F_{1,7}=339.25, R^{2}=0.979, P=0.008$; $F_{1,17}=846.06, R^{2}=0.980, P=0.001$ and Adonis for LPO: $F_{1,7}=78.79, R^{2}=0.918, P=0.008 ; F_{1,17}=100.04$,
$\left.R^{2}=0.855, P=0.001\right)$. These observations indicate that the organisms were not under neurological or oxidative stress. The apparent depression in SOD activity may also have been the result of the different methods applied to assess this enzyme in both studies. Temperature and the sediment sulphide content have been pointed out as factors responsible for the induction of SOD activity in $H$. diversicolor, while anoxia seems to have a non-significant effect on the activity of this enzyme (Abele-Oeschger et al., 1994; Sun \& Zhou, 2008). Thus, the lower temperature to which the ragworms have been exposed in the microcosm, in comparison to the field conditions, may have been responsible for the depression in SOD activity. Such a temperature effect is also likely on the activity of the other tested enzymes, since a similar decreasing trend has been reported for antioxidant enzyme activities in 
invertebrate species with decreasing temperatures (Khessiba et al., 2005; Sroda \& Cossu-Leguille, 2011; Kong et al., 2012). However, the temperatures that produced a significant reduction in the activity of stress biomarkers in the referenced studies were lower than those recorded in the ELSS, and in some cases variation with temperature displayed a sex-dependent tendency (Sroda \& Cossu-Leguille, 2011). Similarly, contradictory relationships between temperature and SOD activity in $H$. diversicolor have been reported (Abele-Oeschger et al., 1994; Sun \& Zhou, 2008). Although the ELSS appeared to induce anaerobic conditions, a sulphide rich environment and to promote the abundance of $\mathrm{SRB}$, our results did not show oxidative stress induction in ragworms.

\section{Experimental life support system applications}

In this study, we have described the development and validation of an experimental microcosm framework capable of simulating fundamental dynamics of coastal systems. Water inorganic nutrient concentrations remained fairly stable during validation trials, exhibiting comparable values to those recorded in the coastal lagoon. Bacterial community structure validation revealed that the microcosm operational programme introduced a shift that favoured the SRB group in particular. However, these changes do not necessarily imply a strong shift in community functioning, given that the most abundant classes were still detected in samples at the end of the experiment. Nevertheless, if deemed necessary, aerobic conditions can be stimulated by choosing different tidal ranges with different percentages of water renewal. At the end of the validation period, the biomarkers of $H$. diversicolor were within the same magnitude of values reported in the literature for organisms collected in the same estuary, under reference conditions.

The ELSS described here can be easily reproduced and operated under a moderate budget. We estimated that the replication of this system would cost approximately 15000 euros. Assuming 0.098 euros per Kilowatt hour $^{-1}$ (average price of electricity for industry in the European Union for the second semester 2012 - http:/ / appsso.eurostat.ec.europa.eu/nui/show.do?dataset=nrg _pc_205\&lang=en), we estimated a daily operational cost of approximately 4.09 euros. If necessary, the system's flexible architecture allows for the replacement of several subsystems to fit specific research needs. Its modular construction enables researchers to employ a multitude of statistically robust complex experimental designs. By changing the pre-sets of our ELSS values with respect to temperature and $\mathrm{pH}$ subsystems, it is possible to simulate several scenarios of global climate change, such as the postulated increase in temperature and reduction in $\mathrm{pH}$ in marine environments. If users choose to use natural seawater and operate under a closed recirculated water system, it is important that other carbonate parameters, such as dissolved inorganic carbon or total alkalinity, are monitored since carbonate chemistry can be affected. Irradiance values can also be manipulated by varying lamp intensity and time of operation. For example, scenarios predicting an increase in UV-B can be simulated by simply removing the glass filter used in our validation trials and by manipulating lamp intensity.

This system can be used to establish cause-effect relationships on the impact of climate change and other anthropogenic stressors on coastal marine benthic communities and processes. For example, the ELSS could be used to study bacterial mediated degradation (e.g. petroleum hydrocarbon degradation) in coastal systems under various climate change scenarios. Hediste diversicolor stress indicators could then be applied to assess the toxicity of degradation products. The data thus obtained can provide the basis for our understanding how climate change and pollution may interact to affect coastal marine ecosystems in the future.

\section{Acknowledgements}

This study was supported by the Centre for Environmental and Marine Studies (CESAM), the Foundation for Science and Technology (FCT, Portugal) PTDC/AAC-CLI/107916/2008 (http://alfa.fct.mctes.pt) and the European Regional Development Fund (ERDF) through COMPETE-(FCOMP-01-0124FEDER-008657). Francisco J.R.C. Coelho and Rui J. M. Rocha were supported by a PhD scholarship (SFRH/BD/46322/2008 and SFRH/BD/46675/2008, respectively) funded by FCT (QREN-POPH - Type 4.1 - Advanced Training, subsidized by the European Social Fund and national funds MCTES). We thank José Ferreira from EpArq, Aveiro University for graphical design of the ELSS. We also wish to thank our anonymous reviewers for their comments and suggestions.

\section{References}

Abele-Oeschger D, Oeschger R, Theede H (1994) Biochemical adaptations of Nereis diversicolor (Polychaeta) to temporarily increased hydrogen peroxide levels in intertidal sandflats. Marine Ecology Progress Series, 106, 101-110.

Aebi H (1984) Catalase in vitro. Methods in Enzymology, 105, 121-126.

Barbier EB, Hacker SD, Kennedy C, Koch EW, Stier AC, Silliman BR (2010) The value of estuarine and coastal ecosystem services. Ecological Monographs, 81, 169-193.

Bargagli R (2005) Antarctic Ecosystems: Environmental Contamination, Climate Change, and Human Impact. Springer-Verlag, Berlin, Germany.

Benton TG, Solan M, Travis JMJ, Sait SM (2007) Microcosm experiments can inform global ecological problems. Trends in Ecology \& Evolution, 22, 516-521.

Bertics VJ, Ziebis W (2010) Bioturbation and the role of microniches for sulfate reduction in coastal marine sediments. Environmental Microbiology, 12, 3022-3034.

Bouraoui Z, Banni M, Ghedira J, Clerandeau C, Narbonne JF, Boussetta H (2009) Evaluation of enzymatic biomarkers and lipoperoxidation level in Hediste diversicolor exposed to copper and benzo[a]pyrene. Ecotoxicology and Environmental Safety, 72, 1893-1898.

Bowman JP (2005) Order VII. Methylococcales ord. nov. In: Bergey's Manual of Systematic Bacteriology (The Proteobacteria), part B (The Gammaproteobacteria), Vol 2, 2nd edn, (eds Brenner DJ, Krieg NR, Staley JT, Garrity GM), pp. 248-225. Springer, New York. 
Bradford MM (1976) A rapid and sensitive method for the quantification of micrograms quantities of protein utilizing the principle of protein-dye binding. Analytical Biochemistry, 72, 248-254.

Buege JA, Aust SD (1978) Microssomal lipid peroxidation. Methods in Enzymology, 52, 302-310.

Cleary DFR (2003) An examination of scale of assessment, logging and ENSOinduced fires on butterfly diversity in Borneo. Oecologia, 135, 313-321.

Cleary DFR, Genner MJ (2004a) Changes in rain forest butterfly diversity following major ENSO-induced fires in Borneo. Global Ecology and Biogeography, 13, 129-140.

Cleary DFR, Mooers AØ, Eichhorn KAO, Van Tol J, De Jong R, Menken SBJ (2004b) Diversity and community composition of butterflies and odonates in an ENSOinduced fire affected habitat mosaic: a case study from East Kalimantan, Indonesia. Oikos, 105, 426-448.

Cleary DFR, Smalla K, Mendonça-Hagler LCS, Gomes NCM (2012) Assessment of variation in bacterial composition among microhabitats in a mangrove environment using DGGE fingerprints and barcoded pyrosequencing. PLOS ONE, 7, e29380.

Connell JH (1978) Diversity in tropical rain forests and coral reefs. Science, 199, 1302-1310.

Dias J, Lopes J, Dekeyser I (2001) Lagrangian transport of particles in Ria de Aveiro lagoon, Portugal. Physics and Chemistry of the Earth, Part B: Hydrology, Oceans and Atmosphere, 26, 721-727.

Doney SC (2010) The Growing human footprint on coastal and open-ocean biogeochemistry. Science, 328, 1512-1516.

Ellman GI, Courtney KD, Andreas V, Featherstone RM (1961) A new and rapid colorimetric determination of acetycholinesterase activity. Biochemical Pharmacology, 7 , 88-95.

Ferreira JG, Simas T, Nobre A, Silva MC, Shifferegger K, Lencart-Silva J (2003) Identification of sensitive areas and vulnerable zones in transitional and coastal Portuguese systems. In: Application of the United States National Estuarine Eutrofication Assessement to the Minho (ed INAG- Instituto da Água and IMAR-Instituto do Mar), pp. 53-65. Ria Formosa and Guadiana Systems, Lima, Douro, Ria de Aveiro, Mondego, Tagus, Sado, Mira.

Gaidos E, Rusch A, Ilardo M (2011) Ribosomal tag pyrosequencing of DNA and RNA from benthic coral reef microbiota: community spatial structure, rare members and nitrogen-cycling guilds. Environmental Microbiology, 13, 1138-1152.

Gao K, Xu J, Gao G et al. (2012) Rising CO2 and increased light exposure synergistically reduce marine primary productivity. Nature Climate Change, 2, 519-523.

Gattuso JP, Lavigne H (2009) Technical Note: approaches and software tools to investigate the impact of ocean acidification. Biogeosciences, 6, 2121-2133.

Gingold R, Mundo-Ocampo M, Holovachov O, Rocha-Olivares A (2010) The role of habitat heterogeneity in structuring the community of intertidal free-living marine nematodes. Marine Biology, 157, 1741-1753.

Gomes NCM, Cleary DFR, Pinto FN et al. (2010) Taking root: enduring effect of rhizosphere bacterial colonization in mangroves. PLOS ONE, 5, e14065.

Habig WH, Pabst MJ, Jakoby WB (1974) Gluthione S-Transferase - the first enzymatic step in mercapturic acid formation. Journal of Biological Chemistry, 240, 7130-7139.

Hader DP, Helbling EW, Williamson CE, Worrest RC (2011) Effects of UV radiation on aquatic ecosystems and interactions with climate change. Photochemical \& Photobiological Sciences, 10, 242-260.

Heuer H, Wieland J, Schönfeld J, Schönwälder A, Gomes NCM, Smalla K (2001) Bacterial community profiling using DGGE or TGGE analysis. In: Environmental Molecular Microbiology: Protocols and Applications, (ed. Rouchelle P), pp. 177-190. Horizon Scientific Press, Wymondham.

Jessup CM, Kassen R, Forde SE, Kerr B, Buckling A, Rainey PB, Bohannan BJM (2004) Big questions, small worlds : microbial model systems in ecology. TRENDS in Ecology and Evolution, 19, 189-197.

Jiang L, Zheng Y, Peng X, Zhou H, Zhang C, Xiao X, Wang F (2009) Vertical distribution and diversity of sulfate-reducing prokaryotes in the Pearl River estuarine sediments, Southern China. FEMS Microbiology Ecology, 70, 249-262.

Keijser BJF, Zaura E, Huse SM et al. (2008) Pyrosequencing analysis of the Oral Microflora of healthy adults. Journal of Dental Research, 87, 1016-1020.

Kersters K, Vos PDE, Gillis M, Swings J, Vandamme P (2006) Introduction to proteobacteria. In: The Prokaryotes, (eds Dworkin M, Falkow S, Rosenberg E, Schleifer K-H, Stackebrandt E), pp. 3-37. Springer, New York.

Khessiba A, Roméo M, Aïssa P (2005) Effects of some environmental parameters on catalase activity measured in the mussel (Mytilus galloprovincialis) exposed to lindane. Environmental Pollution, 133, 275-281

Kong X, Wang G, Li S (2012) Effects of low temperature acclimation on antioxidant defenses and ATPases activities in the muscle of mud crab (Scylla paramamosain). Aquaculture, 370-371, 144-149.

Kristensen E (2001) Impact of polychaetes (Nereis spp. and Arenicola marina) on carbon biogeochemistry in coastal marine sediments. Geochemical Transactions, 2, 92-103.
Kuczynski J, Stombaugh J, Walters WA, González A, Caporaso JG, Knight R (2011) Using QIIME to analyze 16S rRNA gene sequences from microbial communities. Current Protocols in Bioinformatics, 36, 10.7.1-10.7.20.

Laverock B, Smith CJ, Tait K, Osborn AM, Widdicombe S, Gilbert JA (2010) Bioturbating shrimp alter the structure and diversity of bacterial communities in coastal marine sediments. ISME Journal, 4, 1531-1544.

Legendre P, Gallagher E (2001) Ecologically meaningful transformations for ordination of species data. Oecologia, 129, 271-280.

Leser TD (1994) Validation of microbial community structure and ecological functional parameters in an aquatic microcosm designed for testing genetically engineered microorganisms. Microbial Ecology, 29, 183-201.

Limnologisk Metodik (1992) Ferskvandsbiologisk Laboratorium. Københavns Universitet. Akademisk Forlag, København.

Liu Z, Klatt CG, Wood JM et al. (2011) Metatranscriptomic analyses of chlorophototrophs of a hot-spring microbial mat. The ISME journal, 5, 1279-1290.

Lopes CB, Pereira MA, Vale C, Lillebø AI, Pardal MA, Duarte AC (2007). Assessment of spatial environmental quality status in Ria de Aveiro (Portugal). Scientia Marina, 72, 293-304.

Moreira SM, Lima I, Ribeiro R, Guilhermino L (2006) Effects of estuarine sediment contamination on feeding and on key physiological functions of the polychaete Hediste diversicolor: laboratory and in situ assays. Aquatic Toxicology, 78, 186-201.

Muyzer G, Stams AJM (2008) The ecology and biotechnology of sulphate-reducing bacteria. Nature reviews. Microbiology, 6, 441-454.

Nübel U, Engelen B, Felske A, et al. (1996) Sequence heterogeneities of genes encoding 16S rRNAs in Paenibacillus polymyxa detected by temperature gradient gel electrophoresis. Journal of bacteriology, 178, 5636-5643.

Oksanen J, Kind R, Legendre P, O'Hara B, Simpson G (2008) Vegan: Community Ecology Package. $R$ package version 1.15-1. Available at: http://cran.r-project.org/, http:/ /vegan.r-forge.r-project.org/ (accessed 4 May 2012).

Olsen T, Ellerbeck L, Fisher T, Callaghan A, Crane M (2001) Variability in acetylcholinesterase and glutathione S-transferase activities in Chironomus riparius meigen deployed in situ at uncontaminated field sites. Environmental Toxicology and Chemistry, 20, 1725-1732.

Passow U, Carlson CA (2012) The biological pump in a high CO2 world. Marine Ecology Progress Series, 470, 249-271.

Pires ACC, Cleary DFR, Almeida A et al. (2012) Denaturing gradient gel electrophoresis and barcoded pyrosequencing reveal unprecedented archaeal diversity in mangrove sediment and rhizosphere samples. Applied and Environmental Microbiology, $78,5520-5528$.

Reid A (2011) Incorporating microbial processes into climate models. A report from the American Society of Microbiology. 28

Roesch LFW, Fulthorpe RR, Riva A et al. (2007) Pyrosequencing enumerates and contrasts soil microbial diversity. ISME Journal, 1, 283-290.

Roeselers G, Zippel B, Staal M, van Loosdrecht M, Muyzer G (2006) On the reproducibility of microcosm experiments - different community composition in paralle phototrophic biofilm microcosms. FEMS Microbiology Ecology, 58, 169-178.

Scaps P (2002) A review of the biology, ecology and potential use of the common ragworm Hediste diversicolor (O.F. Müller) (Annelida: Polychaeta). Hydrobiologia, 470, 203-218.

Schiedek D, Sundelin B, Readman JW, Macdonald RW (2007) Interactions between climate change and contaminants. Marine Pollution Bulletin, 54, 1845-1856.

Solé M, Kopecka-Pilarczyk J, Blasco J (2009) Pollution biomarkers in two estuarine invertebrates, Nereis diversicolor and Scrobicularia plana, from a Marsh ecosystem in SW Spain. Environment International, 35, 523-531.

Sørensen KB, Canfield DE, Teske AP, Oren A (2005) Community composition of a hypersaline endoevaporitic microbial mat. Applied and Environmental Microbiology, 71, 7352-7365.

Sroda S, Cossu-Leguille C (2011) Seasonal variability of antioxidant biomarkers and energy reserves in the freshwater gammarid Gammarus roeseli. Chemosphere, 83, 538-544.

Sun F-H, Zhou Q-X (2008) Oxidative stress biomarkers of the polychaete Nereis diversicolor exposed to cadmium and petroleum hydrocarbons. Ecotoxicology and Environmental Safety, 70, 106-114.

Urich T, Lanzén A, Qi J, Huson DH, Schleper C, Schuster SC (2008) Simultaneous assessment of soil microbial community structure and function through analysis of the meta-transcriptome. PLOS ONE, 3, e2527.

de Voogd N, Becking L, Cleary D (2009) Sponge community composition in the Derawan Islands, NE Kalimantan, Indonesia. Marine Ecology Progress Series, 396, 169-180.

Weisburg WG, Barns SM, Pelletier DA, Lane DJ (1991) 16S ribosomal DNA amplification for phylogenetic study. Journal of Bacteriology, 173, 697-703.

Zhang W, Song L-S, Ki J-S, Lau C-K, Li X-D, Qian P-Y (2008) Microbial diversity in polluted harbor sediments II: Sulfate-reducing bacterial community assessment using terminal restriction fragment length polymorphism and clone library of dsrAB gene. Estuarine, Coastal and Shelf Science, 76, 682-691. 


\section{Supporting Information}

Additional Supporting Information may be found in the online version of this article:

Figure S1. Lateral front view of the experimental life support system.

Figure S2. Water and tide circulation system detail (Front). A, independent microcosm; B, saltwater reservoir; C, acidified saltwater tide reservoir; D, normal $\mathrm{pH}$ saltwater tide reservoir; E, inlet pipe (to return the exceeding water to the tide reservoir); F, Outlet pipe (to discharge the microcosm waste water after tide circulation).

Figure S3. Water and tide circulation system detail (Back). A, outlet pipe from the microcosm; B, inlet pipe in the microcosm; C, inflow water pump.

Figure S4. Water and tide circulation system detail (top view). A, Outflow pump positioned inside a PVC cylinder and protected with a mesh screen.

Figure S5. $\mathrm{pH}$ control system detail: $\mathrm{A}, \mathrm{CO}_{2}$ bottle; $\mathrm{B}$, solenoid valve; $\mathrm{C}$, $\mathrm{pH}$ controller; $\mathrm{D}$, pH electrode probe.

Figure S6. Water bath detail (from back). A, waterbath (the 2 tanks were drilled in the bottom and connected through a $40 \mathrm{~mm}$ PVC pipe); B, individual microcosm; C, refrigerator; D, canister filter pump; E, Stainless Steel 118 structure $40 \times 2 \mathrm{~mm}$.

Figure S7. Lighting system detail: A, luminaire.

Figure S8. Luminaire detail: A, daylight and ultraviolet lamps dispose alternately.

Figure S9. Experimental light spectra. A, Spectrum of photosynthetically active radiation (PAR: $400-700 \mathrm{~nm}$ ) of the fluorescent tubes set to $100 \%$ intensity.

Figure S10. Average $\mathrm{pH}$ measured during 1 week every 2 days in control and reduced $\mathrm{pH}$ treatments.

Figure S11. Concentration of dissolved inorganic nutrients (nitrate $\mathrm{NO}_{3}{ }^{-}$; ammonium $\mathrm{NH}_{4}{ }^{+}$and o-phosphate $\mathrm{PO}_{4}{ }^{3-}$ ) in water ELSS control at the beginning of the experiment, after 21 days and at the end of the experiment.

Figure S12. Principal coordinates analysis of Denaturing-gradient gel electrophoresis fingerprints of 16S rRNA gene fragments amplified at time 0 (ConBs), 21 days (ConIs) and 57 days (ConFs).

Figure S13. Rarefied OTU richness as a function of the number of sequences from ConBs (environment) and ConFs (microcosm) samples.

Figure S14. Principal coordinates analysis of operational taxonomic unit (OTU) composition.

Figure S15. Heatmap showing the abundance of dominant $16 \mathrm{~S}$ rRNA cDNA sequence reads ( $\geq 50$ sequences).

Table S1. Artificial life support system main components, their manufacturers and suppliers.

Table S2. Diurnal cycles of the PAR and UV integrated radiation intensities expressed as percentages of maxima intensities of the respective fluorescence tubes.

Table S3. The environmental range of water parameters (temperature, salinity and $\mathrm{pH}$ ), and of dissolved inorganic nutrients (nitrate $\mathrm{NO}_{3}{ }^{-}$, ammonium $\mathrm{NH}_{4}{ }^{+}$and o-phosphate $\mathrm{PO}_{4}{ }^{3-}$ ) in Portuguese coastal systems and in the ELSS microcosms (control experimental units). 